\title{
Autonomic Neuropathy in Proliferative Diabetic Retinopathy
}

\author{
CHARLES V. CLARK \\ Edinburgh
}

\begin{abstract}
Summary
Autonomic nerve function was assessed in 28 diabetic patients with proliferative retinopathy and 61 age- and sex-matched control subjects, using a series of tests based upon cardiovascular reflex responses to standardised stimuli. Autonomic neuropathy was present in 75 per cent of diabetics with proliferative retinopathy, compared with 5.2 per cent of the control group. The implications of a significant association between cardiovascular autonomic neuropathy and proliferative diabetic retinopathy are discussed.
\end{abstract}

Autonomic neuropathy has an insidious onset which precludes accurate identification due to the compensatory mechanisms inherent within the autonomic nervous system. Until comparatively recently, tests of autonomic function have been extremely difficult to interpret and almost impossible to quantify. A series of simple, non-invasive tests based upon cardiovascular reflexes have been developed during the past 15 years, permitting accurate, objective and reproducible measurement of autonomic nerve function. . $2,3,4,5,6$ As in all reflex assessments, the subject's output reaction is measured following application of a standardised input stimulus. Results are based upon blood pressure and heart-rate responses to a variety of stimuli, the relative importance of each component of the reflex having been determined by selective pharmacological autonomic blockade. Evidence to date confirms that these tests reflect damage elsewhere in the autonomic nervous system, and represent generalised autonomic nerve function. ${ }^{7,8,9}$
The aim of the present study was to assess systemic autonomic control of cardiovascular function in diabetic patients with abnormal retinal microsvascular proliferation-proliferative retinopathy.

\section{Patients and Methods}

After informed consent had been obtained, cardiovascular autonomic nerve function was assessed in 28 diabetic patients with proliferative retinopathy (mean age $50.8 \pm 14.3$ years) and 61 age- and sexmatched control subjects (mean age 53.1 10.1 years). The diabetic group comprised 21 subjects with IDDM (mean age $46.0 \pm 12.9$ years) and 7 subjects with NIDDM (mean age $65.8 \pm 6.5$ years). The mean duration of diabetes was $20.9 \pm 8.8$ years: IDDM (23.6 \pm 7.3 years); NIDDM (12.6 \pm 7.9 years). The control group consisted of hospital staff and patients attending an ophthalmic casualty department who were subsequently determined to have no detectable abnormality. Subjects with medical disorders predisposing to autonomic nerve dysfunction, or taking medication with effects on the autonomic nervous system, were excluded from the study. A standard series of cardiovascular 
Table I. Cardiovascular autonomic function tests

Parasympathetic nerve function

i. Heart-rate variation during deep breathing

ii. Immediate heart-rate response to standing

iii. Immediate heart-rate response to lying

iv. Valsalva manoeuvre

Sympathetic nerve function

i. Systolic blood pressure response to standing

ii. Diastolic blood pressure response to sustained isometric muscular contraction

autonomic function tests are shown in Table I. These are simple, non-invasive tests, without known side-effects, however there are potential complications in this particular group of patients which required modification of the standard methods. Valsalva manoeuvre and raising blood pressure-as occurs in the diastolic blood pressure response to sustained isometric muscle contraction-involve a rare, potential risk of vitreous haemorrhage in subjects with retinal neovascularisation, and therefore these tests were omitted. The test regimen employed in proliferative retinopathy was therefore:

Parasympathetic nerve function

\section{(i) Heart-rate variation during deep breathing}

There are many different techniques of assessing respiratory sinus arrhythmia;10.11.12.13 one of the standard methods is to request the subject to breathe at a rate of 6 deep breaths/minute, whilst recording a continuous electrocardiogram. In normal subjects, a relative tachycardia occurs during inspiration, with a relative bradycardia during expiration. Maximum and minimum R-R intervals are measured and expressed as beats/minute, and the final result is the mean of the differencès between maximum and minimum heartrates.

\section{(ii) Immediate heart-rate response to standing}

During alteration in posture from lying to standing a characteristic cardiovascular reflex response occurs under vagal control, consisting of an initial tachycardia, maximal at about the 15 th beat after standing, followed by a relative bradycardia around the 30 th beat. $\mathrm{R}-\mathrm{R}$ intervals are measured to determine the shortest around the 15 th beat and longest at about beat 30 , and the result expressed as the $30: 15$ ratio.

(iii) Immediate heart-rate response to lying

A similar, though distinctly separate reflex occurs during alteration in posture from standing to lying. A tachycardia occurs during the 3 rd-4th beat after commencing the manoeuvre; the reflex is represented by the ratio of the longest $R-R$ interval during the 5 beats before lying to the shortest during the 10 beats after lying down.

\section{Sympathetic nerve function}

Systolic blood pressure response to standing A fall in blood pressure is precipitated by gravitational pooling of blood in the lower extremities. Significant fluctuations in blood pressure during alteration in posture is prevented by an intact baroreflex arc, effecting peripheral and splanchnic vasoconstriction via sympathetic efferent nerves. The immediate difference between systolic blood pressure lying and standing is the postural change in blood pressure.

All subjects were in normal sinus rhythm, an essential prerequisite to cardiovascular autonomic function assessment.

Long-term glycaemic control was assessed by glycosylated haemoglobin, using a micro-column technique,,$^{14}$ and an estimation of renal function was obtained by measurement of plasma creatinine. ${ }^{15}$

\section{Statistical analysis}

Comparisons were made between the results of the control group and diabetic patients with proliferative retinopathy; significance was assessed by Student's unpaired t test. Results are expressed as mean \pm SEM.

\section{Results}

The results of cardiovascular autonomic function assessment in 28 diabetic patients with proliferative retinopathy and 61 age- and sexmatched control subjects are shown in Table II. Results of all parasympathetic nerve function tests were significantly lower in diabetics with proliferative retinopathy than the control group, with significance at the 0.1 per cent level. Sympathetic nerve function was not significantly different. Age-adjusted normal tolerance intervals in the control group were calculated for each individual test by linear regression analysis; the data were fitted according to various mathematical models using the computer programme SPSSx on an IBM 4341 computer to obtain a normal distribution on age, thus permitting determination of tolerance intervals. ${ }^{16}$ Values below the 2.5th percentile were arbitrarily designated abnormal. In every test of autonomic nerve function, abnormal values were significantly 
Table II. Results of cardiovascular autonomic function assessment in 28 diabetic patients with proliferative diabetic retinopathy and 61 age- and sex-matched control subjects

(Group mean values \pm SEM)

\begin{tabular}{lrrr}
\hline & Control group & PDR & Significance \\
\hline Parasympathetic nerve function & & & \\
i. Heart-rate variation (beats/min) & $18.24 \pm 0.93$ & $10.08 \pm 1.42$ & $\mathrm{p}<0.001$ \\
ii. 30:15 ratio & $1.17 \pm 0.01$ & $1.07 \pm 0.01$ & $\mathrm{p}<0.001$ \\
iii. S:L & $1.21 \pm 0.01$ & $1.12 \pm 0.01$ & $\mathrm{p}<0.001$ \\
Sympathetic nerve function & & & $\mathrm{p}>0.05$ \\
Postural hypotension (mmHg) & $8.36 \pm 1.42$ & $11.59 \pm 2.99$ & \\
\hline
\end{tabular}

Table III. The proportion of diabetics with proliferative retinopathy and control subjects with abnormal results of cardiovascular autonomic nerve function, defined by the age-adjusted normal tolerance limit at the lower 2.5 th percentile

\begin{tabular}{lcc}
\hline & Control group & PDR \\
\hline Parasympathetic nerve function & & $64.3 \%$ \\
i. Heart-rate variation & $1.3 \%$ & $11.1 \%$ \\
ii. $30: 15$ ratio & $2.6 \%$ & $25.0 \%$ \\
iii. S:L ratio & $1.3 \%$ & \\
Sympathetic nerve function & & $28.6 \%$ \\
Postural hypotension & $2.6 \%$ & \\
\hline
\end{tabular}

elevated in diabetics with proliferative retinopathy (Table III).

Autonomic dysfunction is defined as an abnormal result of at least one autonomic function test. By this criterion, the prevalence of parasympathetic neuropathy in proliferative diabetic retinopathy was 67.9 per cent, with sympathetic neuropthy in 28.6 per cent of patients, compared with values in the control group of 2.6 per cent respectively. Neuropathy involving both parasympathetic and sympathetic nerves was present in 21.5 per cent of diabetics with proliferative retinopathy; no member of the control group had evidence of both parasympathetic and sympathetic neuropathy.

Glycosylated haemoglobin was moderately elevated in diabetics with proliferative retinopathy $(10.3 \pm 0.42$ per cent; normal range 6.0-8.5 per cent). Serum creatinine levels were not excessively abnormal in the diabetic group $(104.5 \pm 8.31 \mu \mathrm{mol} / \mathrm{l}$; normal range 55-110 $\mu \mathrm{mol} / \mathrm{l})$; abnormal results were present in only 5 diabetic patients.

\section{Discussion}

Clinical assessment of autonomic nerve function based upon cardiovascular reflex tests provides an accurate and quantifiable measurement of a nervous system previously virtually impossible to isolate. Heart-rate is determined by the autonomic nervous system, and represents a balance between sympathetic and parasympathetic effects. ${ }^{17,18}$ Although each test may be used individually, the application of a series of tests provides a detailed assessment of systemic autonomic nerve function.

Diabetes mellitus is the commonest cause of autonomic neuropathy in this country; approximately $17-30$ per cent of randomly selected diabetics have abnormal autonomic function, a prevalence confirmed by several large studies. ${ }^{5,19,20,21}$ By definition, this population will include patients with proliferative retinopathy, and therefore the prevalence in diabetics without retinopathy is proportionately less. Cardiovascular autonomic neuropathy is present in 75 per cent of diabetic subjects with proliferative retinopathy, which is the highest prevalence of secondary autonomic neuropathy recorded to date. Glycaemic control and renal function were not excessively abnormal in these patients, and therefore this could not be considered merely a manifestation of severity of diabetes. 
Similarly, duration of diabetes was relatively unremarkable.

In conclusion, this study has demonstrated a significant association between cardiovascular autonomic neuropathy and proliferative diabetic retinopathy. The exact nature of this relationship remains to be defined, however severe impairment of autonomic control of the cardiovascular system may be a contributing factor to the development of retinal neovascularisation in diabetes mellitus.

I thank Dr D. J. Ewing, University of Edinburgh, for advice relating to Autonomic Functional Assessment.

\section{References}

${ }^{1}$ Ewing DJ, Borsey DQ, Bellavere F, Clarke BF: Cardiac autonomic neuropathy in diabetes: comparison of measures of $\mathrm{R}-\mathrm{R}$ interval variation. Diabetologia 1981, 21: 18-24.

${ }^{2}$ Levin AB: A simple tests of cardiac function based upon the heart-rate changes induced by the Valsalva manoeuvre. Am J Cardiol 1966, 18: 90-9.

${ }^{3}$ Ewing DJ, Campbell IW, Murray A, Neilson JMM, Clarke BF: Immediate heart-rate response to standing: simple test for autonomic neuropathy in diabetes. Br Med J 1978, i: 145-7.

${ }^{4}$ Bellavere, F, Ewing DJ: Autonomic control of the immediate heart-rate response to lying down. Clin Sci 1982, 62: 57-64.

${ }^{5}$ Ewing DJ, Irving JB, Kerr F, Wildsmith JAW, Clarke BF: Cardiovascular responses to sustained handgrip in normal subjects and in patients with diabetes mellitus. Clin Sci Mol Med 1974, 46: 295-306.

${ }^{6}$ Hilsted J, Galbo H, Christensen NJ, Parving H-H, Benn J: Haemodynamic changes during graded exercise in patients with diabetic autonomic neuropathy. Diabetologia 1982, 22: 318-23.

${ }^{7}$ Ewing DJ, Campbell IW, Burt AA, Clarke BF: Vascular reflexes in diabetic autonomic neuropathy. Lancet 1973, ii: 1354-6.
${ }^{8}$ Ewing DJ, Campbell IW, Clarke BF: The natural history of diabetic autonomic neuropathy. Quart J Med 1980, 49: 95-108.

${ }^{9}$ Campbell IW, Heading RC, Tothill P, Buist TAS, Ewing DJ, Clarke BF: Gastric emptying in diabetic autonomic neuropathy. Gut 1977, 18: 462-7.

${ }^{10}$ Murray A, Ewing DJ, Campbell IW, Neilson JMM, Clarke BF: $\mathrm{R}-\mathrm{R}$ interval variations in young male diabetics. Br Heart J 1975, 37: 882-5.

${ }^{11}$ Gundersen HJC, Neubauer B: A long-term diabetic autonomic nervous abnormality. Reduced variations in resting heart rate measured by a simple and sensitive method. Diabetologia 1977, 13: 137-40.

${ }^{12}$ Bennett T, Farquhar IK, Hosking DJ, Hampton JR: Assessment of methods for estimating autonomic nervous control of the heart in patients with diabetes mellitus. Diabetes 1978, 27: 1167-74.

${ }^{13}$ Wheeler T, Watkins PJ: Cardiac denervation in diabetes. Br Med J 1973, iv: 584-6.

${ }^{14}$ Baron MD, Shenouda FS, Sonksen PH: Microcolumn method of $\mathrm{HbA}_{1}$ determination. Lancet 1980, i: $1114-6$.

15 Gabriel R: Time to scrap creatinine clearance? $\mathrm{Br}$ Med J 1986, 293: 1119-20.

${ }^{16} \mathrm{Nie} \mathrm{NH}$ : A complete guide to SPSSx language and operations New York: McGraw Hill, 1983.

${ }^{17}$ Higgins CB, VatnerSF, Braunwald E: Parasympathetic control of the heart. Pharmacol Rev 1973, 25: 119-55.

${ }^{18}$ Levy MN: Sympathetic-parasympathetic interactions in the heart. Circ Res 1971, 29: 437-45.

${ }^{19}$ Hulper B, Willms B: Investigations of autonomic diabetic neuropathy of the cardiovascular system. In: FA Gries, HJ Freund, F Rabe and H Berger (eds). Aspects of autonomic neuropathy in diabetes. New York: George Thieme Verlag, 1980: 77-80.

${ }^{20}$ Dyrberg T, Benn J, Christiansen JS, Hilsted J, Nerup J: Prevalence of diabetic autonomic neuropathy measured by simple bedside tests. Diabetologia 1981, 20: 190-4.

${ }^{21}$ Chipps DR, Kraegen EW, Zelenka GS, McNamara ME, Chisholm DJ: Cardiac beat to beat variation: age related changes in the normal population and abnormalities in diabetics. Aust NZ J Med 1981, 11: 614-20. 